\title{
Clinical importance of serum HE4 and MMP2 levels in endometrial cancer patients
}

\author{
This article was published in the following Dove Press journal: \\ OncoTargets and Therapy \\ 27 June 2017 \\ Number of times this article has been viewed
}

\author{
Aneta Cymbaluk-Płoska' \\ Anita Chudecka-Głaz' \\ Ewa Pius-Sadowska ${ }^{2}$ \\ Agnieszka Sompolska- \\ Rzechuła $^{3}$ \\ Bogusław Machaliński \\ Anna Surowiec' \\ Janusz Menkiszak' \\ 'Department of Gynecological \\ Surgery and Gynecological \\ Oncology of Adults and Adolescents, \\ ${ }^{2}$ Department of General Pathology, \\ Pomeranian Medical University, \\ ${ }^{3}$ Department of Statistics, West \\ Pomeranian University of Technology, \\ Szczecin, Poland
}

Introduction: Endometrial cancer is the one of the most common cancers of the genital organ. HE4 and MMP2 are both proteins whose serum levels increase in endometrial cancer.

Aim: To explore the diagnostic potential of the serum levels of HE4 and MMP2 in patients with endometrial cancer and benign endometrial diseases. To assess the relationship between the serum levels of HE4 and MMP2 and the typical prognostic factors in patients with endometrial cancer.

Materials and methods: Included in the study was a group of 112 patients presenting with bleeding abnormalities at the Pomeranian Medical University in years 2012-2016. Serum HE4 concentrations were measured using the Elecsys Electrochemiluminescence Immunoassay (ECLIA). MMP2 concentrations were quantified in the serum using multiplex immunoassays. Results: We observed statistically significant differences in mean serum levels of HE4 and MMP2 between the group of endometrial cancer patients and the group of patients with no changes in the endometrium ( $P=0.002 / 0.003)$. The diagnostic potential of HE4 and MMP2 in differentiation of high (International Federation of Gynecology and Obstetrics [FIGO] III and IV) vs low (FIGO I and II) clinical stage of tumor and prediction of cellular differentiation grade (G1 vs G3) on the basis of the analysis of the area under the curve is, respectively, 0.86 and 0.82 for HE4 and 0.82 and 0.74 for MMP2. The HE4 marker was significantly more specific than MMP2 in every study group and amounted to $93 \%$ vs $86 \%$ in all patients included in the analysis, $94 \%$ vs $84 \%$ in pre-menopausal patients and $84 \%$ vs $79 \%$ in post-menopausal patients.

Conclusion: HE4 and MMP2 are characterized by high specificity and may be useful as biomarkers in the diagnostics of endometrial cancer. When determined preoperatively, HE4 is correlated with the prognostic factors of endometrial cancer and may be helpful in the planning of individual treatment of endometrial cancer patients.

Keywords: MMP2, HE4, endometrial cancer, staging

\section{Introduction}

Endometrial cancer is the second most common cancer of the genital organ. It is discovered quite early, most commonly in patients reporting at the physician's office due to abnormal perimenopausal bleeding. Type I endometrial cancer is diagnosed in $80 \%$ of patients. It is associated with the well-known risk factors such as obesity, hypertension or type II diabetes. Type II endometrial cancer is more often diagnosed in elderly patients. Its histopathological types are associated with poorer prognosis. As in other cancer diseases, the 5-year survival and the likelihood of recurrence depend on the clinical stage and the histopathological type of the tumor. ${ }^{1}$ The vast majority of endometrial cancer patients are characterized by significant obesity and background internal diseases. Radical surgical treatment including iliac and paraaortic lymphadenectomy may be a significant burden to these patients. Therefore, markers that could be helpful
Correspondence: Aneta Cymbaluk-Płoska Department of Gynecological Surgery and Gynecological Oncology of Adults and Adolescents, Pomeranian Medical University, A Powstańców Wielkopolskich 72, 70-I I I Szczecin, Poland Tel +48 9l 466 I3 33

Email anetac@data.pl 
in identification of patients with poorer prognosis are being sought. This is all the more important as the sensitivity of detection by means of imaging methods is in the range of $70 \%-82 \%$ for lymph node metastases ${ }^{2}$ and $40 \%-74 \%$ for the thickness of myometrial infiltration. ${ }^{3}$ Today, overexpression of HE4 in endometrial cancer is being increasingly raised. HE4 is a well-known protein used in the diagnostics of ovarian cancer. ${ }^{4}$ In endometrial cancer, significant overexpression was also observed for metalloproteinase 2 that is strongly associated with invasiveness and proliferation of this disease. ${ }^{5}$

\section{Aim}

1. To explore the behavior and diagnostic potential of the serum levels of HE4 and MMP2 in patients with endometrial cancer and benign endometrial diseases.

2. To assess the relationship between the serum levels of HE4 and MMP2 and the typical risk factors in endometrial cancer patients.

\section{Materials and methods}

Included in the study was a group of 112 patients presenting with bleeding abnormalities at the Pomeranian Medical University in years 2012-2016. Excluded from the study were patients with high creatinine levels, chronic renal diseases, respiratory diseases or circulatory failure, in whom HE4 levels might be elevated in a non-specific manner. Patients were classified as pre-menopausal and post-menopausal according to their hormonal status.

Following the surgical treatment and histopathological examinations, patients were divided into 2 groups, including:

1. patients with endometrial cancer, $n=62$;

2. patients with normal endometrium, $n=50$.

The detailed distribution of patients with endometrial cancer divided into subgroups is given in Table 1.

\section{Methods}

Five milliliters of blood was collected from each patient for determination of HE4 and MMP2. Serum HE4 concentrations were measured using the Elecsys Electrochemiluminescence Immunoassay (ECLIA) from Roche running on the cobas e 601 analyzer. The normal range was $<70 \mathrm{pmol} / \mathrm{L}$ for pre-menopausal women and $<140 \mathrm{pmol} / \mathrm{L}$ for postmenopausal women.

MMP2 assay analysis was performed as follows: $25 \mu \mathrm{L}$ of each standard, control and samples were added to the plate together with multiplex antibody capture bead solution, and the plate was incubated with agitation for 2 hours
Table I Patients with endometrial cancer divided into subgroups

\begin{tabular}{lll}
\hline Subgroups & Distribution & Numbers \\
\hline $\begin{array}{l}\text { The histopathological } \\
\text { type }\end{array}$ & $\begin{array}{l}\text { Type I cancer (endometrial } \\
\text { endometrioid adenocarcinoma) } \\
\text { Type II cancer patients (serous } \\
\text { endometrial carcinoma, } \\
\text { squamous adenocarcinoma and }\end{array}$ & II \\
& clear cell carcinoma) & \\
Histopathological & GI & 13 \\
grade of the tumor & G2 & 28 \\
Clinical stage of the & G3 & 20 \\
tumor & FIGO I and II & 50 \\
Myometrial & Superficial myometrial infiltration & 12 \\
infiltration depth & (<I/2 of the thickness) & \\
& Deep myometrial infiltration \\
(>I/2 of the thickness) & 24 \\
Vascular space & With vascular invasion & 21 \\
involvement & Without vascular invasion & 41 \\
Lymph vessel & With lymph vessel invasion & 30 \\
involvement & Without lymph vessel invasion \\
Lymph node & With lymph node metastases \\
metastases & Without lymph node metastases & 32 \\
\hline Abs & 17 \\
\hline
\end{tabular}

Abbreviation: FIGO, International Federation of Gynecology and Obstetrics.

at room temperature. Subsequently, the well was washed with $200 \mu \mathrm{L}$ wash buffer 2 times by using hand-held magnet. A total of $25 \mu \mathrm{L}$ of detection antibody cocktail was pipetted to each well, and the plate was sealed and incubated at room temperature for 1 hour on a plate shaker. After this step, $25 \mu \mathrm{L}$ of streptavidin-phycoerythrin mixture was added to the plate and incubated with agitation for 30 minutes in dark. Finally, after washing, the microspheres in each well were resuspended in $100 \mu \mathrm{L}$ sheath fluid and shaken at room temperature for 5 minutes. The plate was then read and analyzed on the Luminex analyzer, and analyte concentrations were determined from 5 different standard curves showing median fluorescence intensity (MFI) vs protein concentration.

The statistical analysis was performed using STASTICA 10.0 PL program. The descriptive characteristic of the examined population of patients was determined using minimum, maximum, mean and median values. Since the distributions of studied traits are not normal distributions, positional parameters, medians and non-parametric tests were used to compare median values (Kruskal-Wallis and post hoc Dunn test to compare 3 groups and Mann-Whitney $U$ test to compare 2 groups). For the selected groups, the receiver operating characteristic (ROC) curves were obtained and the area under the curve (AUC) was calculated with $95 \%$ confidence intervals according to the non-parametric method of DeLong. A $P$-value of $<0.05$ was considered as statistically significant. 
Table 2 Comparative analysis of the study groups pre- vs post-menopausal

\begin{tabular}{|c|c|c|c|c|c|c|c|}
\hline \multirow[t]{2}{*}{ Variables } & \multicolumn{3}{|c|}{ Carcinoma endometrium } & \multicolumn{3}{|c|}{ Normal endometrium } & \multirow[t]{2}{*}{$P$-value } \\
\hline & $\mathbf{n}$ & Mean range & $\begin{array}{l}\text { Median }-95.000 \% \text { to } \\
95.000 \%\end{array}$ & $\mathbf{n}$ & Mean range & $\begin{array}{l}\text { Median }-95.000 \% \text { to } \\
95.000 \%\end{array}$ & \\
\hline MMP2, pg/mL & 62 & $5,876.4(4,38||-6,.69 \mid .7)$ & $5,92 \mid .2(5, \mid 23.4-6,342 . I)$ & 50 & $3,624 . I(3,|82|-4,.26 I . I)$ & $3,7 \mid 2 . I(3,25 I .4-4,000 . I)$ & 0.003 \\
\hline MMP2 PM, pg/mL & 62 & $5,360.3(4,2 \mid 4.0-7,521.0)$ & $4,700.0(4,555.507-6,165.2)$ & 50 & $3,7 \mid 7.7(1,876.0-6,578.0)$ & $3,552.5(3,377.8-4,057.6)$ & 0.001 \\
\hline MMP2 M, pg/mL & 62 & $5,578.6(4,321.0-6,831.0)$ & $5,893.0(4,8|0.4| 3-5,946.9)$ & 50 & 3,6 II.3 (3,09।.3-4,87।.I) & $3,681.1(3,109.2-3,999.2)$ & 0.01 \\
\hline HE4, pmol/L & 62 & $92.1(61.0-104.0)$ & $95.0(64.852-86.4)$ & 50 & $55.5(43.0-81.0)$ & $60.0(46.0-63.0)$ & 0.002 \\
\hline HE4 PM, pmol/L & 62 & $88.6(67.0-116.0)$ & $91.3(72.3-103.4)$ & 50 & $51.8(43.7-69.1)$ & $55.1(48.2-65.8)$ & 0.004 \\
\hline HE4 M, pmol/L & 62 & III.I (67.0-26I.0) & $165.0(107.7-132.4)$ & 50 & $64.3(49.0-88.0)$ & $60.0(58.8-68.7)$ & $<0.001$ \\
\hline
\end{tabular}

Abbreviations: PM, premenopause; $M$, menopause.

\section{Ethical approval}

Resolution number: KB-0012/77/12 of the Bioethics Committee of the Pomeranian University of Medicine in Szczecin of 13 October 2012.

All procedures performed in studies involving human participants were in accordance with the ethical standards of the institutional and/or national research committee and with the 1964 Declaration of Helsinki and its later amendments or comparable ethical standards.

\section{Informed consent}

Written informed consent was provided by the patients and the physician. All the patients have signed informed consent for the study, which has been signed and initialed by the doctor on each side. Patients read carefully the information and were able to ask questions.

\section{Results}

\section{Comparative analysis of the study groups}

Table 2 presents the patients' characteristics and the mean levels and comparisons of the tested proteins. We observed statistically significant differences in mean serum levels of HE4 and MMP2 between the group of endometrial cancer patients and the group of patients with bleeding abnormalities and no changes within the endometrium, both as regards the entire study population as in the individual hormonal status subgroups (pre- vs post-menopausal).

\section{Comparative analysis according to the prognostic factors}

Tables 3 and 4 present the values and comparisons of HE4 and MMP2 serum levels depending on various prognostic factors. In our analysis of all the currently established adverse risk factors of endometrial cancer, we found out that there are no statistically significant differences in HE4 and MMP2 levels between both types of cancer (I vs II) and between G1 and G2 tumors. However, the differences in HE4 levels were closer to the statistical significance threshold, with median levels amounting to $89.6 \mathrm{pmol} / \mathrm{L}$ in endometrioid-type tumors and $101.1 \mathrm{pmol} / \mathrm{L}$ in non-endometrioid-type tumors, $P=0.053$.

No differences in serum MMP2 levels were also observed for different blood vessel invasion status and different endometrial infiltration depths, while significantly higher MMP2 levels were observed in poorly differentiated tumors compared to well-differentiated tumors $(P=0.02)$, high-stage tumors compared to low-stage tumors $(P=0.001)$ and tumors with positive status of lymph vessel invasion $(P=0.02)$ and lymph node metastases $(P=0.003)$.

The serum levels of HE4 were significantly higher in poorly differentiated tumors $(P=0.007)$, high-stage tumors

Table 3 Comparative analysis according to the prognostic factors for HE4

\begin{tabular}{|c|c|c|c|c|c|c|}
\hline & Mean & Median & Min & Max & Standard deviation & $P$-value \\
\hline Age, years & 57.5 & 54 & 40 & 78 & 10.0 & - \\
\hline Endometrioid/non-endometrioid & $89.6 / 101.2$ & $90.2 / 99.8$ & $83 / 88$ & $102 / 113$ & $8.2 / 8.8$ & 0.053 \\
\hline GI/G2 & $73.1 / 81.8$ & $74.1 / 83.0$ & $61 / 69.3$ & $88 / 96$ & $7.6 / 8.4$ & 0.061 \\
\hline GI/G3 & $73.1 / 106.2$ & $74.1 / 109.3$ & $61 / 85.4$ & $88 / 126$ & $7.6 / 9.4$ & 0.007 \\
\hline FIGO I and II/FIGO III and IV & $62.3 / 110.8$ & $65.4 / 107.9$ & $56.3 / 91.0$ & $83.2 / 131.0$ & $9.1 / 12.8$ & 0.002 \\
\hline Vascular invasion \pm & $68.6 / 107.3$ & $69.3 / 109.2$ & $65.2 / 94.2$ & $83.2 / 117.2$ & $8.1 / 9.6$ & 0.001 \\
\hline Lymph vessels invasion \pm & $74.0 / 105.1$ & $77.0 / 108.1$ & $70.1 / 92.0$ & $96 / 119.6$ & $8.6 / 10.2$ & 0.004 \\
\hline Lymph nodes metastasis \pm & $81.2 / 122.1$ & $78.8 / 119.6$ & $68.9 / 104.2$ & $92.1 / 136.6$ & $9.7 / 11.4$ & 0.005 \\
\hline Infiltrate the myometrium superficial/deep & $76.2 / 118.6$ & $78.1 / 120.4$ & $71.1 / 107.2$ & $89.2 / 139.2$ & $7.9 / 13.1$ & 0.0002 \\
\hline
\end{tabular}

Abbreviations: Min, minimum; Max, maximum; FIGO, International Federation of Gynecology and Obstetrics. 
Table 4 Comparative analysis according to the prognostic factors for MMP2

\begin{tabular}{|c|c|c|c|c|c|c|}
\hline & Mean & Median & Min & Max & Standard deviation & $P$-value \\
\hline Age, years & 57.5 & 54 & 40 & 78 & 10.0 & \\
\hline Endometrioid/non-endometrioid & $5,7 \mid 2 / 5,588$ & $5,688 / 5,422$ & $5,284 / 5,044$ & $6,002 / 5,994$ & $1,3 \mid 3 / 1,202$ & 0.07 \\
\hline $\mathrm{GI} / \mathrm{G} 2$ & $5,166 / 5,321$ & $5,090 / 5,288$ & $4,233 / 4,818$ & $6,788 / 6,231$ & $1,210 / 1,480$ & 0.08 \\
\hline GI/G3 & $5,166 / 6,003$ & $5,090 / 5,899$ & $4,233 / 4,67 \mid$ & $6,788 / 6,311$ & $I, 240 / I, \mid, 88$ & 0.02 \\
\hline FIGO I and II/FIGO III and IV & $5,204 / 5,878$ & $5,24|/ 5,8| 3$ & $4,621 / 5,588$ & $6,021 / 6,668$ & $\mathrm{I}, \mathrm{II} \mid \mathrm{I} / \mathrm{I}, 088$ & 0.001 \\
\hline Vascular invasion \pm & $5,688 / 5,515$ & $5,616 / 5,392$ & $5,231 / 5,088$ & $5,989 / 6,002$ & $1,5 \mid 2 / 1,482$ & $>0.05$ \\
\hline Lymph vessels invasion \pm & $5,82 \mathrm{I} / 5,20 \mathrm{I}$ & $5,761 / 5,050$ & $4,42 I / 4, \mid 88$ & $6,2 \mid 4 / 5,910$ & $|, 823 / I, 7| I$ & 0.02 \\
\hline Lymph nodes metastasis \pm & $5,921 / 5,102$ & $5,864 / 5,023$ & $5,001 / 4,107$ & $6,843 / 5,232$ & $\mathrm{I}, 863 / 1,710$ & 0.003 \\
\hline Infiltrate the myometrium superficial/deep & $5,723 / 5,568$ & $5,631 / 5,422$ & $5,088 / 5,|6|$ & $6,231 / 5,888$ & $\mathrm{I}, 366 / 1,088$ & $>0.05$ \\
\hline
\end{tabular}

Abbreviations: Min, minimum; Max, maximum; FIGO, International Federation of Gynecology and Obstetrics.

$(P=0.002)$ and tumors with blood vessel involvement ( $P=0.001)$, lymph vessel invasion $(P=0.004)$, lymph node metastases $(P=0.005)$ and larger myometrial infiltration depths $(P=0.0002)$.

\section{Analysis of ROC curves, assay sensitivity and specificity}

In order to evaluate the diagnostic values of HE4 and MMP2, ROC curves were plotted and the AUCs were calculated. For HE4, the AUC values were 0.92 for all study patients, 0.92 for pre-menopausal patients and 0.86 for post-menopausal patients. The AUC values for MMP2 were 0.79, 0.98 and 0.71 , respectively (Figures $1-4$ ). The diagnostic potential of HE4 and MMP 2 in differentiation of high (International Federation of Gynecology and Obstetrics [FIGO] III and IV) vs low (FIGO I and II) clinical stage of tumor and prediction of cellular differentiation grade (G1 vs G3) on the basis of the analysis of the AUC is, respectively, 0.86 and 0.82 for HE4 and 0.82 and 0.74 for MMP2. The curves are presented in Figures 5 and 6 . Table 5 presents the sensitivity and specificity values for HE4 and MMP2 according to the hormonal status of patients. Higher sensitivity was observed for MMP2 in all patients included in

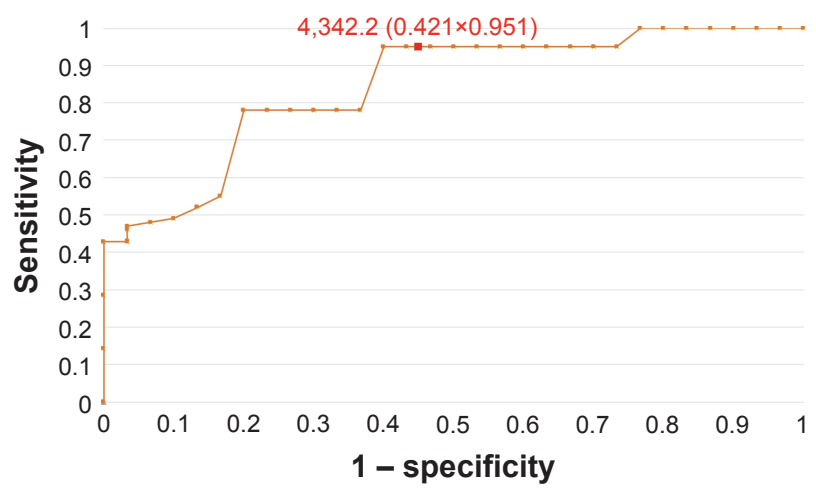

Figure I The ROC curve for MMP2 protein in patients without division due to the hormonal status ( $A \cup C=0.79$ ).

Abbreviations: ROC, receiver operating characteristic; AUC, area under the curve. the analysis (68\%) and in post-menopausal patients (67\%) compared to HE4 (67\% and $64 \%$, respectively). In premenopausal patients, the sensitivity was higher for HE4 (78\%) than for MMP2 (73\%). On the other hand, the HE4 marker was significantly more specific than MMP2 in every study group and amounted to $93 \%$ vs $86 \%$ in all patients included in the analysis, $94 \%$ vs $84 \%$ in pre-menopausal patients and $84 \%$ vs $79 \%$ in post-menopausal patients.

\section{Discussion}

Since 2011, when Food and Drug Administration (FDA) approved HE4 as a marker for use in the diagnostics of ovarian cancer, its blood levels are studied and the possibilities are being explored for its use in diagnostics and monitoring of other tumors, including endometrial cancer. In our studies, the serum levels of HE4 were significantly higher in endometrial cancer patients in both pre- and post-menopausal women. This was in line with the results obtained by Angioli et al. ${ }^{6}$ Similar data were reported by Liu et al, ${ }^{7}$ who, while comparing the possibilities for early detection of endometrial cancer by means of Ca125 and HE4, demonstrated that HE4 is more sensitive and specific regardless of the age and the hormonal status of patients. Gasiorowska et $\mathrm{al}^{8}$

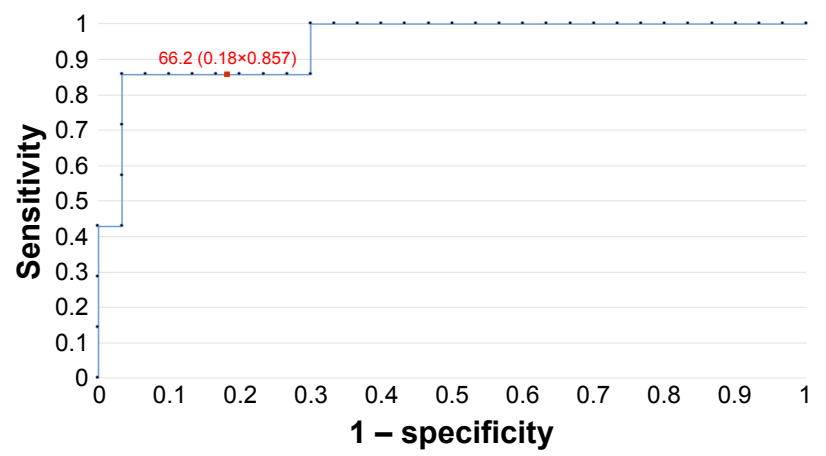

Figure 2 The ROC curve for HE4 protein in patients without division due to the hormonal status (AUC $=0.92$ ).

Abbreviations: ROC, receiver operating characteristic; AUC, area under the curve. 


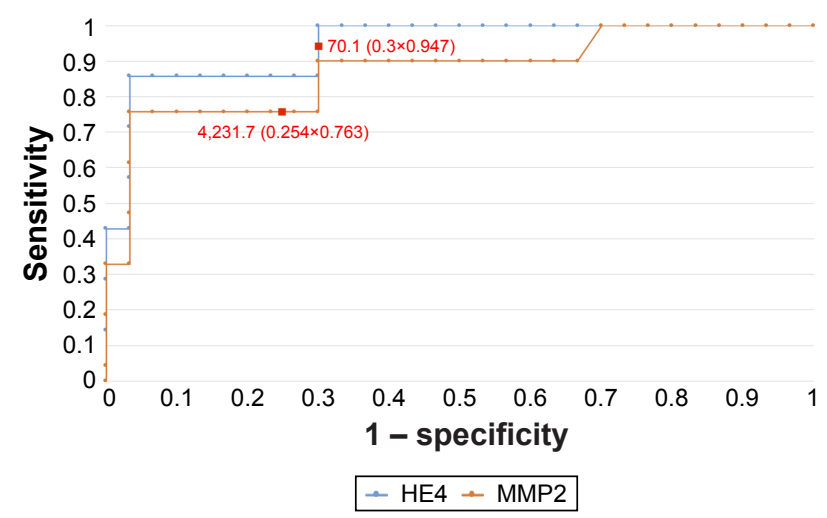

Figure 3 The ROC curves for HE4 and MMP2 proteins in patients before menopause (AUC $=0.92 / 0.84)$.

Abbreviations: ROC, receiver operating characteristic; AUC, area under the curve.

reported that the threshold HE4 level indicating the cutoff between benign endometrial lesions and endometrial cancer was $58.08 \mathrm{pmol} / \mathrm{L}$. In our case, this value was slightly higher and amounted to $66.2 \mathrm{pmol} / \mathrm{L}$.

Available in the literature are two meta-analyses that assess the possibilities for using HE4 in early detection of endometrial cancer. The sensitivity and specificity of the detection of endometrial cancer on the basis of single HE4 measurements were $56 \%$ and $89 \%{ }^{9}$ and $59 \%$ and $92 \%$, respectively. ${ }^{10}$ Bie and Zhang ${ }^{10}$ and $\mathrm{Hu}$ et $\mathrm{al}^{9}$ highlighted that HE4 is more sensitive than Ca125; however, the results were unsatisfactory. In our studies, we were able to achieve the sensitivity at the level of $67 \%$ with the specificity at the level of $93 \%$.

Also compared was the high expression of HE4 in endometrial cancer tissues compared to benign endometrial pathologies, amounting to $85.7 \%$ and $16.7 \%$, respectively. ${ }^{11}$ In addition, tissue expression was observed to be higher in endometrial cancer compared to atypical endometrial hyperplasia, amounting to $84.6 \%$ and $66.6 \%$, respectively. ${ }^{4}$

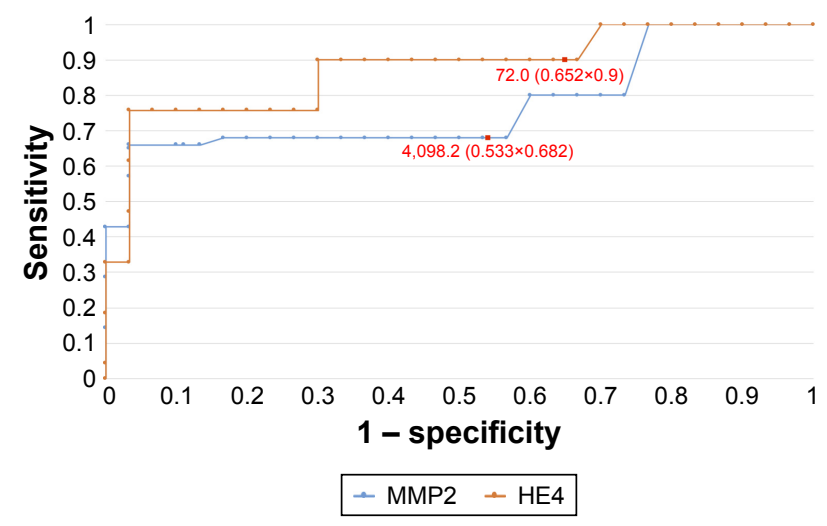

Figure 4 The ROC curves for HE4 and MMP2 proteins in post-menopausal women $(\mathrm{AUC}=0.86 / 0.7 \mathrm{I})$.

Abbreviations: ROC, receiver operating characteristic; AUC, area under the curve.

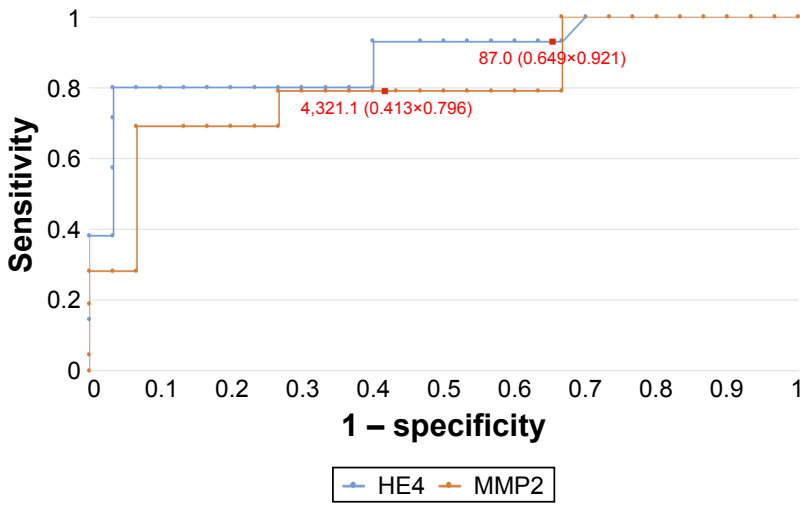

Figure $\mathbf{5}$ The ROC curves for HE4 and MMP2 proteins depending on staging (AUC $=0.86 / 0.82$ ).

Abbreviations: ROC, receiver operating characteristic; AUC, area under the curve.

The most recent studies by Chen et $\mathrm{al}^{12}$ showed that MACC1 plays an important role in endometrial cancer, as its high expression confirmed in vivo in endometrial cancer cell lines was correlated with high expression of MMP2. MACC1 is currently considered a key regulator in the development of numerous cancers. Also numerous other authors pointed to the high expression of MMP2 in patients with endometrial cancer. ${ }^{5,13,14}$ Guo et $\mathrm{al}^{15}$ demonstrated that active MMP2 constitutes the main form of the protein in endometrial cancer, as confirmed by means of electrophoretic assay.

To date, no reports are available on the serum levels of MMP2, comparing the levels of the protein in the serum of patients with endometrial cancer to that in patients with normal endometrium. In our studies, we observed that the levels of MMP2 in endometrial cancer patients were statistically significantly higher than those in patients with normal endometrium. The sensitivity and specificity of the protein in the detection of endometrial cancer were $68 \%$ and $86 \%$, respectively. The values are comparable to those obtained

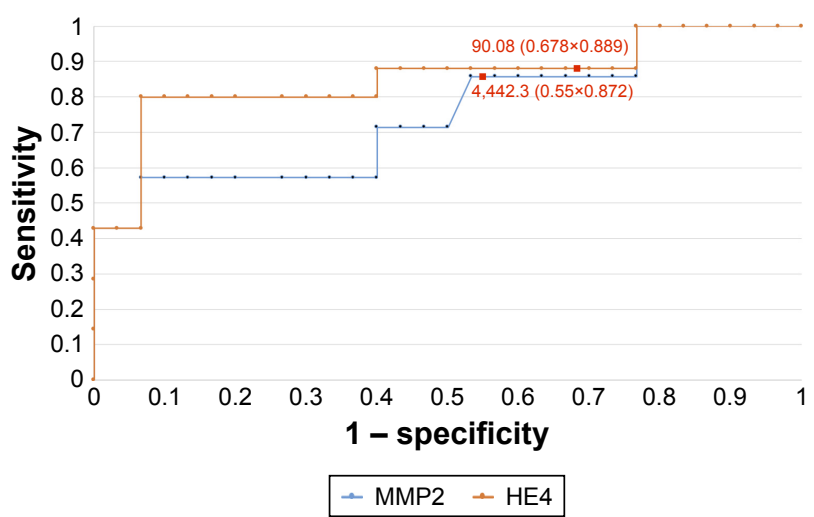

Figure 6 The ROC curves for HE4 and MMP2 proteins in GI and G3 grading $(\mathrm{AUC}=0.82 / 0.74)$.

Abbreviations: ROC, receiver operating characteristic; AUC, area under the curve. 
Table 5 Sensitivity and specificity values for HE4 and MMP2

\begin{tabular}{lll}
\hline & HE4 & MMP2 \\
\hline Sensitivity & $67 \%$ & $68 \%$ \\
Specificity & $93 \%$ & $86 \%$ \\
Sensitivity PM & $78 \%$ & $73 \%$ \\
Specificity PM & $94 \%$ & $84 \%$ \\
Sensitivity M & $64 \%$ & $67 \%$ \\
Specificity M & $84 \%$ & $79 \%$ \\
\hline
\end{tabular}

Abbreviations: PM, premenopause; M, menopause.

for HE4. The respective AUC values for MMP2 compared to HE4 were 0.77 and 0.83 . Angioli et $\mathrm{al}^{6}$ highlighted that ultrasound scans and serum HE4 measurements allow for better preoperative assessment of the clinical stage of tumor than NMR (with the sensitivity values of $96.3 \%$ and $91 \%$, respectively), facilitating significant reduction in the costs of diagnostic examinations.

Angioli et $\mathrm{a}^{6}$ demonstrated statistically significant differences in HE4 levels in patients with different types of endometrial cancer. ${ }^{6}$ In our studies, serum HE4 levels were higher in patients with type II endometrial cancer, albeit no statistical significance threshold was achieved, in line with the results obtained by other authors. ${ }^{16-18}$

Similarly to Abdalla et a ${ }^{18}$ and Dobrzycka et al, ${ }^{19}$ we observed no differences in HE4 levels between the subgroups of patients with well- and moderately differentiated endometrial tumors while observing statistically significant differences between the subgroups of patients with well- and poorly differentiated endometrial tumors.

Other studies demonstrated that patients with welldifferentiated G1 endometrial tumors of low clinical staging had their serum HE4 levels significantly lower than patients with G3 tumors of FIGO stages III and IV. The authors suggested that this observation could be used in the future to identify patients requiring systemic lymphadenectomy. ${ }^{10}$ Capriglione et $\mathrm{al}^{20}$ observed that the serum HE4 levels were statistically significantly higher for all negative prognostic factors (low histopathological differentiation, high stage, blood vessel and lymph vessel involvement and lymph node metastases). ${ }^{20}$ These reports are in line with our results including the HE4 levels being higher in patients with the involvement of lymphatic and blood vessels and in patients with tumor metastases into the lymph nodes. Yilmaz et al and Kemik et al confirmed that in endometrial cancer patients, HE4 marker may be used for individual treatment planning. . $^{21,22}$

The differences in the expression of MMP2 for different histopathological types of tumors were not determined. In our studies, MMP2 levels were found to be higher in non-endometrioid carcinomas than in endometrioid adenocarcinomas. Karahan et $\mathrm{al}^{23}$ and $\mathrm{Chen}$ et $\mathrm{al}^{12}$ demonstrated that
MMP2 expression was much higher in patients with higher clinical stage of the disease. Higher expression of MMP2 in higher tumor stage patients was also demonstrated in immunohistochemical studies by Graesslin et $\mathrm{al}^{24}$ and $\mathrm{Li}$ et al. ${ }^{25}$ We observed that the serum MMP2 levels were markedly higher in patients with higher clinical stage of the disease (FIGO III and IV). However, we are aware that the reports on high tissue expression are not completely comparable to those on high serum levels.

We were also able to observe statistically significant differences in MMP2 levels between the well- and poorly differentiated endometrial cancer. Talvensaari-Mattila et al, who conducted their studies only in type I endometrial cancer patients, observed that the overexpression of MMP2 in the tissues was correlated with tumor differentiation and was thus associated with poorer prognosis. MMP2 was overexpressed in $100 \%$ of poorly differentiated tumors compared to only $70 \%$ in well-differentiated tumors. ${ }^{13}$ Similar reports were presented by Li et al, ${ }^{25}$ Graesslin et al, ${ }^{24}$ Guo et al, ${ }^{15}$ and Karahan et al, ${ }^{23}$ who considered MMP2 to be a marker facilitating identification of patients with higher likelihood of both local and distant metastases. In our study, higher serum MMP2 levels were observed in patients with lymph node metastases and lymphatic vessel involvement but not in patients with deep myometrial infiltration or blood vessel involvement. Guo et al demonstrated a markedly higher expression of MMP2 for deeper myometrial infiltration.

\section{Conclusion}

Both human epididymal epithelial cell protein subfraction 4 and metalloproteinase 2 are characterized by high specificity and may be useful as biomarkers in the diagnostics of endometrial cancer. When determined preoperatively, HE4 is correlated with the prognostic factors of endometrial cancer and may be helpful in the planning of individual treatment of endometrial cancer patients.

\section{Disclosure}

The authors report no conflicts of interest in this work.

\section{References}

1. Felix AS, Yang HP, Bell DW, Sherman ME. Epidemiology of endometrial carcinoma: etiologic importance of hormonal and metabolic influences. Adv Exp Med Biol. 2017;943:3-46.

2. Alcazar JL, Pineda L, Martinez-Astorquiza Corral T, et al. Transvaginal/ transrectal ultrasound for assessing myometrial invasion in endometrial cancer: a comparison of six different approaches. J Gynecol Oncol. 2015; 26(3):201-207

3. Sanjuan A, Cobo T, Pahisa J, et al. Preoperative and intraoperative assessment of myometrial invasion and histologic grade in endometrial cancer: role of magnetic resonance imaging and frozen section. Int $J$ Gynecol Cancer. 2006;16(1):385-390. 
4. Li X, Gao Y, Tan M, et al. Expression of HE4 in endometrial cancer and its clinical significance. Biomed Res Int. 2015;2015:437468.

5. Wang D, Wang D, Wang N, Long Z, Ren X. Long non-coding RNA BANCR promotes endometrial cancer cell proliferation and invasion by regulating MMP2 and MMP1 via ERK/MAPK signaling pathway. Cell Physiol Biochem. 2016;40(3-4):644-656.

6. Angioli R, Capriglione S, Scaletta G, et al. The role of HE4 in endometrial cancer recurrence: how to choose the optimal follow-up program. Tumour Biol. 2016;37(4):4973-4978.

7. Liu X, Zhao F, Hu L, Sun Y. Value of detection of serum human epididymis secretory protein 4 and carbohydrate antigen 125 in diagnosis of early endometrial cancer of different pathological subtypes. Onco Targets Ther. 2015;8:1239-1243.

8. Gasiorowska E, Magnowska M, Izycka N, Warchol W, NowakMarkwitz E. The role of HE4 in differentiating benign and malignant endometrial pathology. Ginekol Pol. 2016;87(4):260-264.

9. Hu L, Du S, Guo W, Chen D, Li Y. Comparison of serum human epididymis protein 4 and carbohydrate antigen 125 as markers in endometrial cancer: a meta-analysis. Int J Gynecol Cancer. 2016;26(2): 331-340.

10. Bie Y, Zhang Z. Diagnostic value of serum HE4 in endometrial cancer: a meta-analysis. World J Surg Oncol. 2014;12:169.

11. Deng L, Gao Y, Li X, et al. Expression and clinical significance of annexin A2 and human epididymis protein 4 in endometrial carcinoma. $J$ Exp Clin Cancer Res. 2015;34(1):96.

12. Chen S, Zong ZH, Wu DD, Sun KX, Liu BL, Zhao Y. The role of metastasis-associated in colon cancer 1 (MACC1) in endometrial carcinoma tumorigenesis and progression. Mol Carcinog. 2016;56(4): 1361-1371.

13. Talvensaari-Mattila A, Santala M, Soini Y, Turpeenniemi-Hujanen T. Prognostic value of matrix metalloproteinase-2 (MMP-2) expression in endometrial endometrioid adenocarcinoma. Anticancer Res. 2005; 25(6B):4101-4105.

14. Honkavuori-Toivola M, Santala M, Soini Y, Turpeenniemi-Hujanen T, Talvensaari-Mattila A. Combination of strong MMP-2 and weak TIMP-2 immunostainings is a significant prognostic factor in endometrial carcinoma. Dis Markers. 2013;35(4):261-266.

15. Guo W, Chen G, Zhu C, Wang H. [Expression of matrix metalloproteinase-2, 9 and it's tissue inhibitor-1, 2 in endometrial carcinoma]. Zhonghua Fu Chan Ke Za Zhi. 2002;37(10):604-607.
16. Bignotti E, Ragnoli M, Zanotti L, et al. Diagnostic and prognostic impact of serum HE4 detection in endometrial carcinoma patients. Br J Cancer. 2011;104(9):1418-1425.

17. Brennan DJ, Hackethal A, Metcalf AM, et al; ANECS Group. Serum HE4 as a prognostic marker in endometrial cancer - a population based study. Gynecol Oncol. 2014;132(1):159-165.

18. Abdalla N, Piorkowski R, Stanirowski P, Slomka A, Cendrowski K, Sawicki W. Assessment of levels of the tumor markers HE4 and CA125 considering staging, grading and histological types of endometrial cancer. Prz Menopauzalny. 2016;15(3):133-137.

19. Dobrzycka B, Mackowiak-Matejczyk B, Terlikowska KM, Kinalski M, Terlikowski SJ. Utility of HE4 to identify patients with endometrioid endometrial cancer who may require lymphadenectomy. Adv Med Sci. 2016;61(1):23-27.

20. Capriglione S, Plotti F, Miranda A, et al. Further insight into prognostic factors in endometrial cancer: the new serum biomarker HE4. Expert Rev Anticancer Ther. 2017;17(1):9-18.

21. Kemik P, Saatli B, Yildirim N, et al. Diagnostic and prognostic values of preoperative serum levels of YKL-40, HE-4 and DKK-3 in endometrial cancer. Gynecol Oncol. 2016;140(1):64-69.

22. Yilmaz SA, Altinkaya SO, Kerimoglu OS, et al. The role of human epididymis secretory protein E4 in patients with endometrial cancer and premalignant endometrial lesions. J Obstet Gynaecol. 2017; 37(1):58-63.

23. Karahan N, Guney M, Baspinar S, Oral B, Kapucuoglu N, Mungan T Expression of gelatinase (MMP-2 and MMP-9) and cyclooxygenase-2 (COX-2) in endometrial carcinoma. Eur J Gynaecol Oncol. 2007; 28(3):184-188.

24. Graesslin O, Cortez A, Fauvet R, Lorenzato M, Birembaut P, Darai E. Metalloproteinase-2, -7 and -9 and tissue inhibitor of metalloproteinase-1 and -2 expression in normal, hyperplastic and neoplastic endometrium: a clinical-pathological correlation study. Ann Oncol. 2006;17(4):637-645.

25. Li S, Shen X, Yang Z, et al. [Clinical significance of MMP2 overexpression in endometrial adenocarcinoma]. Nan Fang Yi Ke Da Хие Хие Вао. 2014;34(3):423-425.
OncoTargets and Therapy

\section{Publish your work in this journal}

OncoTargets and Therapy is an international, peer-reviewed, open access journal focusing on the pathological basis of all cancers, potential targets for therapy and treatment protocols employed to improve the management of cancer patients. The journal also focuses on the impact of management programs and new therapeutic agents and protocols on

\section{Dovepress}

patient perspectives such as quality of life, adherence and satisfaction. The manuscript management system is completely online and includes a very quick and fair peer-review system, which is all easy to use. Visit http://www.dovepress.com/testimonials.php to read real quotes from published authors. 